\title{
Degenerative cervical myelopathy
}

\author{
So Kato ${ }^{1}$ - Michael Fehlings ${ }^{1,2,3}$
}

Published online: 1 June 2016

(C) Springer Science+Business Media New York 2016

\begin{abstract}
Cervical myelopathy is the most common cause of acquired spinal cord compromise. The concept of degenerative cervical myelopathy (DCM), defined as symptomatic myelopathy associated with degenerative arthropathic changes in the spine axis, is being introduced. Given its progressive nature, treatment options have to be chosen in a timely manner. Surgical options include anterior discectomy and fusion (ACDF), anterior corpectomy and fusion (ACCF), arthroplasty (in highly select cases), posterior laminectomy with/without fusion, and laminoplasty. Indications for each should be carefully considered in individual patients. Riluzole, a sodium-glutamate antagonist, is a promising option to optimize neurologic outcomes post-surgery and is being examined in the CSM-Protect Randomized Controlled Trial. Preoperative risk assessment is mandatory for prognostication. Sagittal alignment is known to play an important role to optimize surgical outcome. Guidelines for optimal management of DCM are in process. In principle, all but the mildest cases of DCM should be offered surgery for optimal outcome.
\end{abstract}

Keywords Degenerative cervical myelopathy $\cdot$ Non-surgical treatment - Surgical treatment - Approach · Adjuvant therapy · Prognosis

This article is part of the Topical Collection on Cervical Injuries and Treatment

Michael Fehlings

michael.fehlings@uhn.ca

1 Krembil Neuroscience Centre, Toronto Western Hospital, University Health Network, Toronto, ON, Canada

2 Krembil Research Institute, Toronto Western Hospital, University Health Network, Toronto, ON, Canada

3 Division of Neurosurgery, Toronto Western Hospital, 399 Bathurst St. Suite 4WW-449, Toronto, ON M5T2S8, Canada

\section{Introduction}

Degenerative cervical myelopathy (DCM) is a leading cause of acquired spinal cord compromise [1]. Aside from various other underlying conditions, degenerative change to the vertebral column is by far the leading cause of DCM. Degeneration can happen in many locations in the spinal column, including arthropathy of facet joints and/or intervertebral discs as well as ligamentous aberration (hypertrophy, calcification, or ossification) in the ligamentum flavum and/or posterior longitudinal ligament (Fig. 1). We are introducing the comprehensive concept of DCM defined as symptomatic cervical myelopathy associated with a broad variety of degenerative changes of the extradural spinal tissues $[2,3 \bullet]$. The major conditions falling under the umbrella term DCM have been previously well known as cervical spondylotic myelopathy (CSM) and ossification of the posterior longitudinal ligament (OPLL).

Establishing the standard of care for DCM is extremely important in our aging societies, given its increased prevalence in the elderly population. On the other hand, there are a number of controversies with regards to the management of DCM. Considerable numbers of studies with contradictory results are found in the literature and guidelines have yet to be developed. In the present paper, we reviewed the studies published in the last 3 years focusing on the treatment options and prognosis, and update the current strategies for the management of DCM.

\section{Non-surgical treatment}

Non-surgical treatments, also described as conservative treatments, currently used in the management of DCM include physical therapy, spinal injection, immobilization by collars, and cervical traction. Evidence for the efficacy of non-surgical treatment for DCM is scarce. Rhee et al. and Ghobrial et al. separately published systematic reviews with regard to non- 


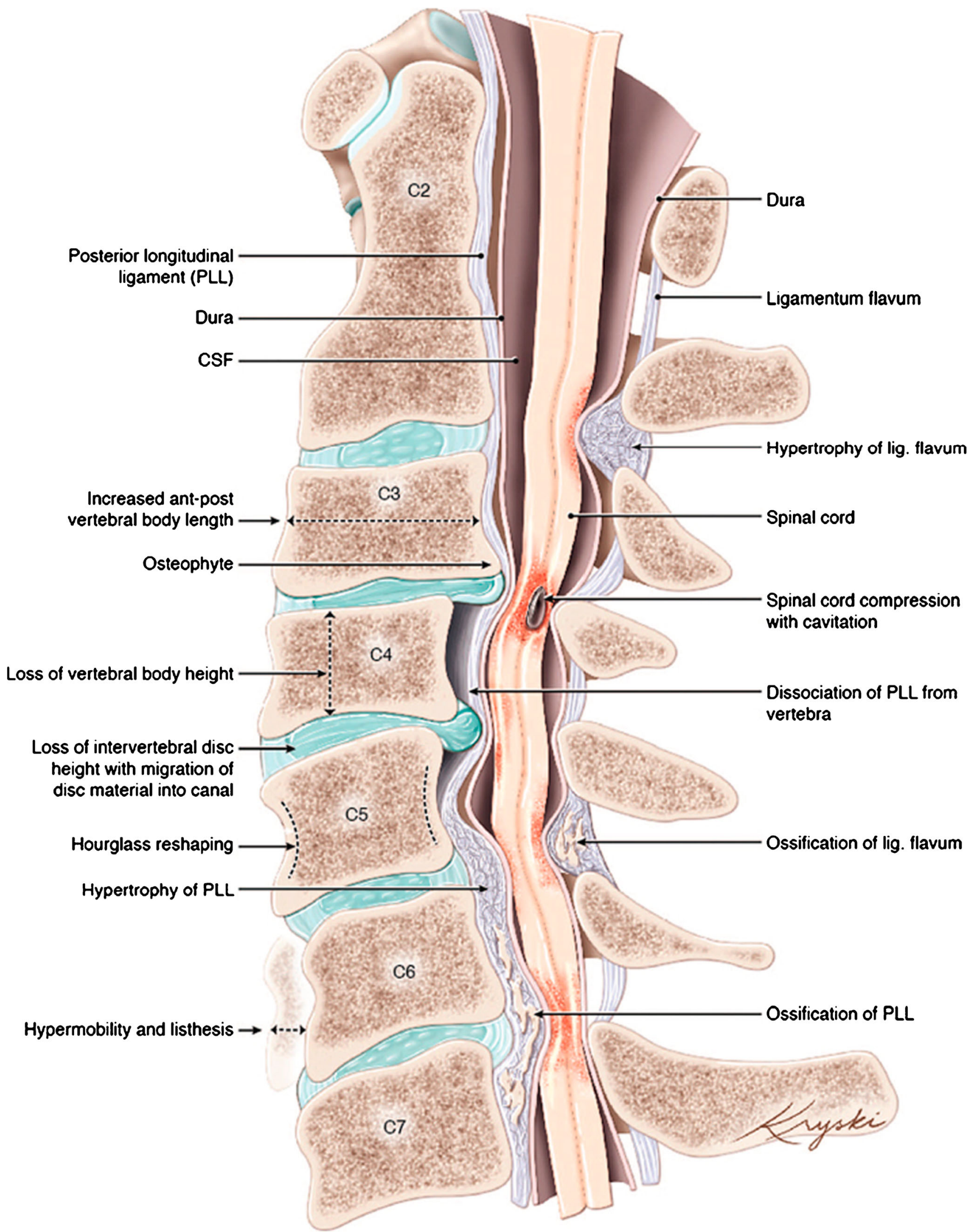

Fig. 1 An artistic depiction of the pathobiology of degenerative cervical myelopathy [3•]. Medical illustration by Diana Kryski (Kryski Biomedia), reused with permission. PLL indicates posterior longitudinal ligament, $C S F$ cerebrospinal fluid 
surgical management, and both concluded that the effectiveness may be greatly dependent on the individuals $[4 \bullet, 5]$. In particular, there is weak evidence that non-surgical treatment has some role in the management of mild myelopathy. Kadanka et al. performed a small randomized controlled trial and showed surgical outcome was not superior in mild myelopathy patients [6], but no further studies have been published and more research in the area is warranted. For moderate to severe myelopathy, surgery is generally the only treatment option given its progressive nature [7, 8]. Risk stratification of symptom progression at the early stage of presentation is also important in order to understand which cases are more likely to progress and are thus more likely to benefit from early intervention.

\section{Surgical treatment}

\section{Anterior approach versus posterior approach}

The fundamental strategies for the operative management of DCM are well established and most of them entail decompression with or without fusion of the spinal column. However, consensus has not been met in terms of whether surgical approach should be made from the anterior or posterior direction. As spinal cord compromise is caused by various lesions in DCM, compression may occur anteriorly (disc, osteophyte, or OPLL), posteriorly (hypertrophy or ossification of ligamentum flavum), and the concept of decompression performed from the side of major compressive factors seems to be straightforward and well accepted. For example, it may be that superior outcomes result from anterior decompression for OPLL with more than $60 \%$ of canal occupying ratio [9-12]. However, DCM can frequently be associated with multiple degenerative lesions and compression can be circumferential. One of the advantages of posterior surgery is the ease of accessing multilevel compression [13]. Therefore, determining the approach is not always straightforward. Common anterior approach surgeries include discectomy and fusion (ACDF), corpectomy and fusion (ACCF), and arthroplasty, while laminectomy with or without fusion and laminoplasty are used for posterior surgery. Two illustrative cases are shown for anterior approach (Fig. 2) and posterior approach (Fig. 3). Although previous literature did not have a consensus on the superiority of one approach over another $[14,15]$, more recent meta-analyses have shown that multilevel anterior surgery up to three levels is superior to posterior surgeries in some aspects including post-operative outcome and alignment but also that anterior surgery is associated with higher rate of reoperation $[13,16-19,20 \bullet]$. Overall surgical complication rates were also reported to be higher in anterior surgery than in posterior surgery, but the spectrum of complications is very different between the two groups and it should be interpreted with caution. Comparative studies are limited, and the conclusions drawn are mixed likely because of their selection biases [21-25]. Further investigations by multicenter prospective controlled trials are warranted.

\section{Anterior decompression and fusion versus arthroplasty}

Smith and Cloward first developed anterior decompression with disc removal $[26,27]$. Today, it usually entails putting a graft in the disc space and adding a plate for fixation. However, for a single level lesion, disc replacement can be a good alternative to fusion surgery. Instead of conventional $\mathrm{ACDF}$, by inserting the prosthesis in the disc, its motion sparing technique can theoretically avoid adjacent segment degeneration and could be potentially promising for younger patients. Long-term outcomes for arthroplasty are still under investigation, and the implant related costs appear to be higher in comparison to anterior fusions. Both prospective [28-33] and retrospective studies [34-36] have been reported, and meta-analyses showed that disc replacement is equivalent or superior to fusion surgery [37-41]. Its superiority in costeffectiveness is still questionable [42-44] and long-term studies will be needed. Of note, arthroplasty is principally an option in patients with DCM who have minimal spondylosis and cord compression from a soft disc herniation - this is an unusual clinical scenario.

\section{Anterior fusion by discectomy versus corpectomy}

For a multilevel stenosis, ACCF can be considered instead of multiple ACDF. With the same surgical approach as ACDF, ACCF entails vertebral body resection with disc removal at both ends as well as reconstruction by a strut graft instead of using a spacer in the disc space in ACDF. Corpectomy is especially useful in cases of bony compression at the level of the vertebral body. It also enables wide decompression and provides a satisfactory amount of autograft. Compared to multilevel ACDFs, ACCF fusions rely on bony healing at two interfaces adjacent to the graft and, theoretically, may lead to higher fusion rates. However, there may be a higher rate of complications with a corpectomy including excessive bleeding and graft dislodgement. For these reasons, its superiority has not been established. Only a small number of retrospective analyses have been done [45-50], and no randomized trials have been reported. Several meta-analyses indicated that ACDF is associated with less surgical complications and better post-operative alignment [51-55].

\section{Laminectomy with or without fusion versus laminoplasty}

The laminoplasty procedure was originally developed by Japanese surgeons as an effective treatment option for congenital cervical stenosis [56, 57]. Its aim is to expand and 


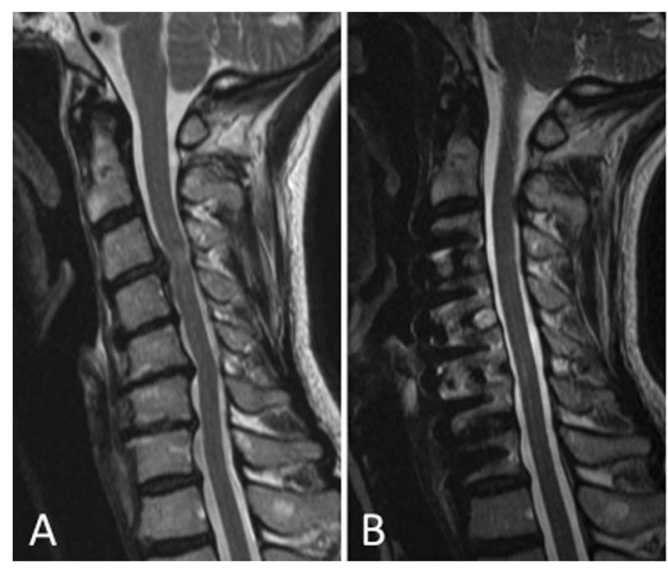

Fig. 2 An illustrative case of anterior surgery. Multiple level spinal cord compression by degenerative discs with mild kyphosis was treated by 4-level anterior cervical discectomy and fusion (C3-7). Optimal decompression was achieved in each level and the post-operative

reconstruct the posterior arch and to prevent post-operative kyphosis (a frequent complication seen post-laminectomy) [58]. Disadvantages of laminoplasty are the technical difficulty in foraminal decompression, potential neurological damage, and higher cost when utilized with the implants. Lately, a newer modification of conventional laminectomy known as "skip laminectomy" which involves preserving muscle attachments to the spinous processes has been introduced, and its effectiveness has been compared with laminoplasty [59-61]. Based on these facts, literature reviews have concluded that the superiority of laminoplasty has not been justified [62, 63].

Laminectomy with instrumented fusion is more commonly performed in North America. Using the same but wider exposure than laminoplasty, fixation is usually achieved by lateral mass screw fixations in the subaxial spine and occasionally also pedicle screw fixations in the upper thoracic spine. It results in the loss of post-

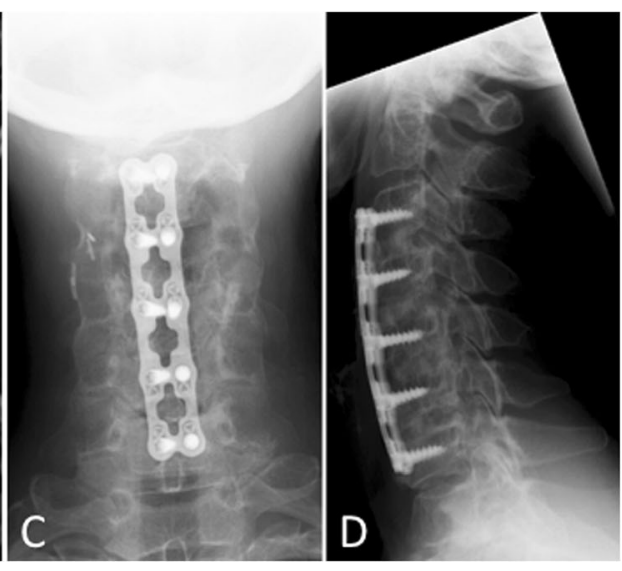

alignment was lordotic by the reconstruction. a Preoperative T2 weighted MRI sagittal image, b post-operative T2 weighted MRI sagittal image, c post-operative antero-posterior radiograph, d post-operative lateral radiograph operative mobility in the cervical spine as compared to laminoplasty, but it more effectively prevents postoperative kyphosis. Therefore laminectomy and fusion is preferred over laminoplasty in those with preoperative kyphosis or potential instability [64-66]. Otherwise, its selection is usually based on surgeons' preference and comparative studies are very limited [67, 68]. Recent systematic reviews have indicated that they are equally effective with similar post-operative outcome, but laminectomy and fusion may result in better alignment in the long term [69-71].

\section{Complications}

Complications specific to surgeries for DCM include dysphagia, pseudarthrosis, C5 palsy, and axial pain. Numerous risk factor analyses have been published recently $[72 \bullet \bullet]$.

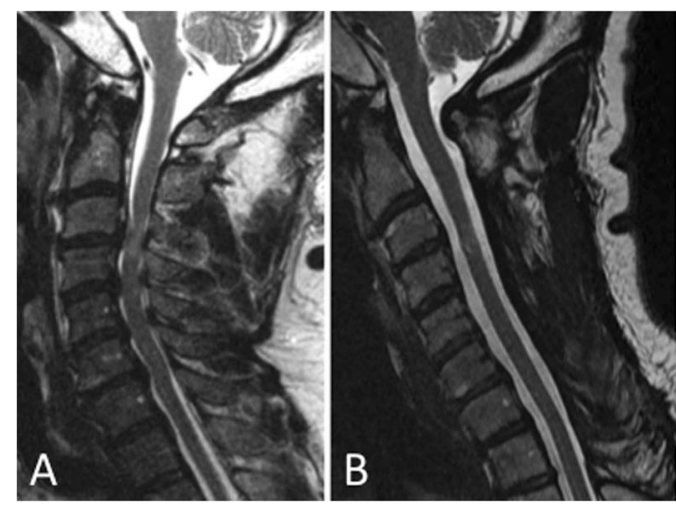

Fig. 3 An illustrative case of posterior surgery. Multiple level spinal cord compression by degenerative discs and ligamentum flavum hypertrophy was treated by posterior laminectomy and fusion (C2-T1). Solid fixation were achieved at both ends of the construct by $\mathrm{C} 2$ pars screws and $\mathrm{T} 1$

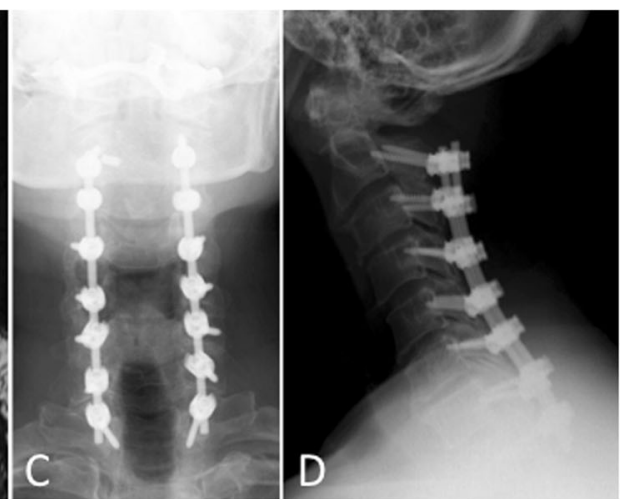

pedicle screws. a Preoperative T2 weighted MRI sagittal image, b post-operative T2 weighted MRI sagittal image, c post-operative antero-posterior radiograph, $\mathbf{d}$ post-operative lateral radiograph 
Dysphagia is a well-known complication after anterior surgeries [73]. Multilevel surgery and bone morphogenetic protein have been raised as risk factors [74, 75]. Newer low profile implants and perioperative steroid administration were shown to be effective in reducing dysphagia by reducing retropharyngeal edema $[76,77]$. Non-union rate after ACDF has been reported to be $2.6 \%$, and use of autograft resulted in better fusion rates in comparison to allograft [78]. C5 palsy is reported both in anterior and posterior surgery, although the risk is higher in posterior laminectomy and fusion [79]. The other risk factors include preoperative foraminal stenosis, OPLL, and asymmetric decompression [80-82]. C5 palsy may be preventable by prophylactic foraminotomy [83]. Axial pain is commonly reported as a posterior neck and scapular pain after laminoplasty. Attempts have been made to decrease the rate by preserving the muscle attachments to the spinous processes $[84,85]$.

In addition to these, cervical spine surgery can cause rare but devastating complications due to its anatomical proximity to critical structures. Esophageal injury is one of these and can be caused by direct injury or by forceful retraction during the anterior approach. It can also occur as a late complication related to malpositioned screws or plates. Unless treated adequately in a timely fashion, it results in fatal infections including mediastinitis [86]. In a cross-sectional study led by the Cervical Spine Research Society, another complication, vertebral artery injury, was found to occur in $0.07 \%$ of their members' cases both with anterior and posterior surgeries [87]. Vertebral artery injury can also be associated with aberrant vasculature and thus careful radiographic preoperative planning is warranted. Although direct injury to the carotid artery is extremely rare, the meticulous hemostasis of its branches is required in order to avoid hematoma formation. In terms of neurological structures, the recurrent laryngeal nerve and the sympathetic chain are at risk. Transient hoarseness after the anterior approach is almost universal in patients after this surgery, but permanent vocal cord palsy can also occur, related to the recurrent laryngeal nerve. The right side approach may increase risk of this complication while decuffing of the endotracheal tube may decrease the risk [88]. Damage to the sympathetic chain can cause Horner's syndrome, which is characterized by ptosis, meiosis, and anhidrosis.

\section{Adjuvant therapy}

Neuroprotective agents may become a common mode of augmenting surgical treatment. Riluzole is an anticonvulsant that functions as a sodium-channel blocker. It is thought to attenuate the ischemia-related excitotoxicity in spinal cord injury models. A phase I trial for traumatic spinal cord injury has already been published, and it showed the preferable recovery in those who received riluzole at 90 days after admissions [89]. Although there are certain differences in pathobiology from traumatic spinal cord injury, ischemia due to the anterior vessel compressions and the deformation in microangiostructure are also the main mechanisms of neural damage in DCM and it is reasonable to extrapolate its effectiveness in these populations. It has already been shown to have promising results in a rodent model of CSM [90, 91]. Fehlings et al. have started a multicenter double-blinded randomized controlled trial to assess the potential neurological benefits as a complementary strategy to surgical decompression [92•]. They are enrolling patients with degenerativerelated spinal cord compression and a modified Japanese Orthopaedic Association (mJOA) score of less than 14 who underwent surgical decompression, and randomly assigning to the riluzole group or the placebo group. The riluzole group receives a dose of $50 \mathrm{mg}$ every $12 \mathrm{~h}$ for 14 days preoperatively and 28 days post-operatively. The comparison of neurological recovery will be made at 6 months post-operatively using mJOA as a primary outcome.

\section{Prognosis and outcomes}

\section{Predictors of outcome}

Since the surgical indication for DCM is determined based on the clinical symptoms and the radiographic findings as well as patients' characteristics and demands, it is important for the surgeons to be able to predict the outcome and offer the best solutions at the appropriate timing for each patient. Although multiple studies have been published, the clinical predictors for poor outcome after decompression surgery were similar in many of them. Worse preoperative neurological status (baseline mJOA), gait impairment, smoking, older age, psychiatric comorbidities, and longer duration from the onset of symptoms to surgical treatment have been flagged $[12,93,94 \cdot \bullet$, 95-101]. Tetreault et al. created a prediction model using the covariates raised above in 278 patients enrolled in the AOSpine CSM North American study and validated this in 479 patients in AOSpine CSM International study [94••, 98, 102]. Radiographically, T2 signal hyperintensity on MRI and more than $60 \%$ of occupying ratio in OPLL are also noted [12, 103-105].

\section{Importance of sagittal balance/alignment on treatment/outcomes}

Cervical sagittal alignment with optimal lordosis has been known to be associated with post-operative quality of life in fusion surgery, but it is now revealed that it also affects the severity of myelopathy symptoms and post-operative outcomes after the decompression [106]. Kyphosis is thought to play an important role in the development of DCM by spinal cord tethering by the dentate ligaments and nerve roots, 
and also by angiostructural change [107]. Indeed, Smith et al. and Mohanty et al. showed that mJOA correlated with C2-C7 sagittal vertical axis in preoperative patients [108, 109]. Preoperative kyphosis has also been identified as a risk factor for inferior surgical outcomes both in anterior and posterior surgery $[12,65,110,111,112 \cdot]$. Although it is still unclear whether post-operative realignment has a positive impact on the outcome, we should note that post-operative outcome was better after anterior surgery for DCM with kyphosis in Shamji et al.'s study [112•]. Aggressive realignment by posterior reconstruction should be avoided since it can result in the foraminal compression whereas anterior reconstruction increases disc height and opens the foramens.

\section{Future directions}

Establishing the standard of care for DCM is challenging. First, the pathology of DCM consists of multiple factors, each of which is may have an ideal approach and the treatment modality has to be chosen differently. Second, diversity in patients backgrounds is increasing, especially considering the aging society prevailing internationally. Their goals and demands have to be carefully considered depending on the risks associated with the treatment options they possess. Finally, we now have more surgical options due to the development of newer techniques and technologies. Numerous authors have advocated that they all showed the promising results in individual studies, but comparative evidence and longterm results are still lacking. Furthermore, the optimal timing for the surgical intervention is unclear. Given that duration of the symptoms has a negative impact on the surgical outcome, timely intervention is mandatory to obtain the optimal results. Clear thresholds of symptoms and durations should be determined so that surgeons can make evidence-based decisions. Efforts are being made to establish the management guideline for DCM. The expert meetings have been led by Fehlings et al. under the auspices of AOSpine North America and the Cervical Spine Research Society. These guidelines are expected to make a significant contribution to help all health care providers involved in care of DCM to provide the best management.

\section{Conclusions}

Despite considerable progress having been made in terms of deeper understanding of cervical myelopathy and development of safe and effective treatment options, there still remain many controversies with regard to optimal management of cervical myelopathy. Surgeons have to be aware of pros and cons of each strategy and its prognosis and should be able to propose the best possible care for the individual patients. To choose the optimal treatment in a timely fashion, the establishment of guidelines is strongly indicated.

\section{Compliance with ethical standards}

Conflict of interest So Kato and Michael Fehlings declare that they have no conflict of interest.

Human and animal rights and informed consent This article does not contain any studies with human or animal subjects performed by any of the authors.

\section{References}

Papers of particular interest, published recently, have been highlighted as:

- Of importance

•• Of major importance

1. Fehlings MG, Wilson JR, Kopjar B, et al. Efficacy and safety of surgical decompression in patients with cervical spondylotic myelopathy: results of the AOSpine North America prospective multi-center study. J Bone Joint Surg Am. 2013;95:1651-8.

2. Tetreault L, Goldstein CL, Arnold P, et al. Degenerative cervical myelopathy: a spectrum of related disorders affecting the aging spine. Neurosurgery. 2015;77 Suppl 4:S51-67.

3. Nouri A, Tetreault L, Singh A, et al. Degenerative cervical myelopathy: epidemiology, genetics, and pathogenesis. Spine (Phila Pa 1976). 2015;40:E675-93. Recent narrative review introducing degenerative cervical myelopathy with its detailed description.

4. Rhee JM, Shamji MF, Erwin WM, et al. Nonoperative management of cervical myelopathy: a systematic review. Spine (Phila Pa 1976). 2013;38:S55-67. Systematic review of evidences regarding nonoperative treatment of cervical myelopathy. They concluded nonoperative treatment is not routinely recommended given the paucity of evidence.

5. Ghobrial GM, Harrop JS. Surgery vs conservative care for cervical spondylotic myelopathy: nonoperative operative management. Neurosurgery. 2015;62 Suppl 1:62-5.

6. Kadanka Z, Bednarik J, Novotny O, et al. Cervical spondylotic myelopathy: conservative versus surgical treatment after 10 years. Eur Spine J. 2011;20:1533-8.

7. Fehlings MG, Wilson JR, Yoon ST, et al. Symptomatic progression of cervical myelopathy and the role of nonsurgical management: a consensus statement. Spine (Phila Pa 1976). 2013;38: S19-20.

8. Ghogawala Z, Benzel EC, Riew KD, et al. Surgery vs conservative care for cervical spondylotic myelopathy: surgery is appropriate for progressive myelopathy. Neurosurgery. 2015;62 Suppl 1: 56-61.

9. An HS, Al-Shihabi L, Kurd M. Surgical treatment for ossification of the posterior longitudinal ligament in the cervical spine. J Am Acad Orthop Surg. 2014;22:420-9.

10. Epstein NE. What you need to know about ossification of the posterior longitudinal ligament to optimize cervical spine surgery: a review. Surg Neurol Int. 2014;5:S93-S118.

11. Fujimori T, Iwasaki M, Okuda S, et al. Long-term results of cervical myelopathy due to ossification of the posterior longitudinal 
ligament with an occupying ratio of $60 \%$ or more. Spine (Phila Pa 1976). 2014;39:58-67.

12. Kim B, Yoon do H, Shin HC. Surgical outcome and prognostic factors of anterior decompression and fusion for cervical compressive myelopathy due to ossification of the posterior longitudinal ligament. Spine J. 2015;15:875-84.

13. Liu X, Min S, Zhang H, et al. Anterior corpectomy versus posterior laminoplasty for multilevel cervical myelopathy: a systematic review and meta-analysis. Eur Spine J. 2014;23:362-72.

14. Alvin MD, Lubelski D, Benzel EC, et al. Ventral fusion versus dorsal fusion: determining the optimal treatment for cervical spondylotic myelopathy. Neurosurg Focus. 2013;35:E5.

15. Lawrence BD, Jacobs WB, Norvell DC, et al. Anterior versus posterior approach for treatment of cervical spondylotic myelopathy: a systematic review. Spine (Phila Pa 1976). 2013;38:S17382.

16. Zhu B, Xu Y, Liu X, et al. Anterior approach versus posterior approach for the treatment of multilevel cervical spondylotic myelopathy: a systemic review and meta-analysis. Eur Spine J. 2013;22:1583-93.

17. Liu X, Wang H, Zhou Z, et al. Anterior decompression and fusion versus posterior laminoplasty for multilevel cervical compressive myelopathy. Orthopedics. 2014;37:e117-22.

18. Jiang L, Tan M, Dong L, et al. Comparison of anterior decompression and fusion with posterior laminoplasty for multilevel cervical compressive myelopathy: a systematic review and meta-analysis. J Spinal Disord Tech. 2015;28:282-90.

19. Sun Y, Li L, Zhao J, et al. Comparison between anterior approaches and posterior approaches for the treatment of multilevel cervical spondylotic myelopathy: a meta-analysis. Clin Neurol Neurosurg. 2015;134:28-36.

20. Luo J, Cao K, Huang S, et al. Comparison of anterior approach versus posterior approach for the treatment of multilevel cervical spondylotic myelopathy. Eur Spine J. 2015;24:1621-30. The most recent systematic review with meta-analysis investigating the outcome of anterior and posterior approach for multilevel cervical myelopathy.

21. Lin D, Zhai W, Lian K, et al. Anterior versus posterior approach for four-level cervical spondylotic myelopathy. Orthopedics. 2013;36:e1431-6.

22. Fehlings MG, Barry S, Kopjar B, et al. Anterior versus posterior surgical approaches to treat cervical spondylotic myelopathy: outcomes of the prospective multicenter AOSpine North America CSM study in 264 patients. Spine (Phila Pa 1976). 2013;38: 2247-52.

23. Seng C, Tow BP, Siddiqui MA, et al. Surgically treated cervical myelopathy: a functional outcome comparison study between multilevel anterior cervical decompression fusion with instrumentation and posterior laminoplasty. Spine J. 2013;13:723-31.

24. Qian L, Shao J, Liu Z, et al. Comparison of the safety and efficacy of anterior 'skip' corpectomy versus posterior decompression in the treatment of cervical spondylotic myelopathy. J Orthop Surg Res. 2014;9:63

25. Kanchiku T, Imajo Y, Suzuki H, et al. Results of surgical treatment of cervical spondylotic myelopathy in patients aged 75 years or more: a comparative study of operative methods. Arch Orthop Trauma Surg. 2014;134:1045-50.

26. Cloward RB. The anterior approach for removal of ruptured cervical disks. J Neurosurg. 1958;15:602-17.

27. Smith GW, Robinson RA. The treatment of certain cervical-spine disorders by anterior removal of the intervertebral disc and interbody fusion. J Bone Joint Surg Am. 1958;40-A:607-24.

28. Phillips FM, Lee JY, Geisler FH, et al. A prospective, randomized, controlled clinical investigation comparing PCM cervical disc arthroplasty with anterior cervical discectomy and fusion. 2-year results from the US FDA IDE clinical trial. Spine (Phila Pa 1976). 2013;38:E907-18.

29. Rozankovic M, Marasanov SM, Vukic M. Cervical disc replacement with discover versus fusion in a single level cervical disc disease: a prospective single center randomized trial with a minimum two-year follow-up. J Spinal Disord Tech. 2014.

30. Gornet MF, Burkus JK, Shaffrey ME, et al. Cervical disc arthroplasty with PRESTIGE LP disc versus anterior cervical discectomy and fusion: a prospective, multicenter investigational device exemption study. J Neurosurg Spine. 2015:1-16.

31. Hisey MS, Bae HW, Davis RJ, et al. Prospective, randomized comparison of cervical total disk replacement versus anterior cervical fusion: results at 48 months follow-up. J Spinal Disord Tech. 2015;28:E237-43.

32. Phillips FM, Geisler FH, Gilder KM, et al. Long-term outcomes of the US FDA IDE prospective, randomized controlled clinical trial comparing PCM cervical disc arthroplasty with anterior cervical discectomy and fusion. Spine (Phila Pa 1976). 2015;40:674-83.

33. Yao Q, Liang F, Xia Y, et al. A meta-analysis comparing total disc arthroplasty with anterior cervical discectomy and fusion for the treatment of cervical degenerative diseases. Arch Orthop Trauma Surg. 2015.

34. Caruso R, Pesce A, Marrocco L, et al. Anterior approach to the cervical spine for treatment of spondylosis or disc herniation: long-term results. Comparison between ACD, ACDF, TDR. Clin Ter. 2014;165:e263-70.

35. Tracey RW, Kang DG, Cody JP, et al. Outcomes of single-level cervical disc arthroplasty versus anterior cervical discectomy and fusion. J Clin Neurosci. 2014;21:1905-8.

36. Zhu R, Yang H, Wang Z, et al. Comparisons of three anterior cervical surgeries in treating cervical spondylotic myelopathy. BMC Musculoskelet Disord. 2014;15:233.

37. Boselie TF, Willems PC, van Mameren H, et al. Arthroplasty versus fusion in single-level cervical degenerative disc disease: a Cochrane review. Spine (Phila Pa 1976). 2013;38:E1096-107.

38. Traynelis VC, Arnold PM, Fourney DR, et al. Alternative procedures for the treatment of cervical spondylotic myelopathy: arthroplasty, oblique corpectomy, skip laminectomy: evaluation of comparative effectiveness and safety. Spine (Phila Pa 1976). 2013;38:S210-31.

39. Xing D, Ma XL, Ma JX, et al. A meta-analysis of cervical arthroplasty compared to anterior cervical discectomy and fusion for single-level cervical disc disease. J Clin Neurosci. 2013;20: 970-8.

40. Luo J, Gong M, Huang S, et al. Incidence of adjacent segment degeneration in cervical disc arthroplasty versus anterior cervical decompression and fusion meta-analysis of prospective studies. Arch Orthop Trauma Surg. 2015;135:155-60.

41. Zhang Y, Liang C, Tao Y, et al. Cervical total disc replacement is superior to anterior cervical decompression and fusion: a metaanalysis of prospective randomized controlled trials. PLoS One. 2015; 10:e0117826.

42. Qureshi SA, McAnany S, Goz V, et al. Cost-effectiveness analysis: comparing single-level cervical disc replacement and singlelevel anterior cervical discectomy and fusion: clinical article. J Neurosurg Spine. 2013;19:546-54.

43. Warren D, Andres T, Hoelscher C, et al. Cost-utility analysis modeling at 2-year follow-up for cervical disc arthroplasty versus anterior cervical discectomy and fusion: a single-center contribution to the randomized controlled trial. Int J Spine Surg. 2013;7: e58-66.

44. McAnany SJ, Overley S, Baird EO, et al. The 5-year cost-effectiveness of anterior cervical discectomy and fusion and cervical disc replacement: a Markov analysis. Spine (Phila Pa 1976). 2014;39:1924-33. 
45. Burkhardt JK, Mannion AF, Marbacher S, et al. A comparative effectiveness study of patient-rated and radiographic outcome after 2 types of decompression with fusion for spondylotic myelopathy: anterior cervical discectomy versus corpectomy. Neurosurg Focus. 2013;35:E4.

46. Odate $\mathrm{S}$, Shikata J, Kimura H, et al. Hybrid decompression and fixation technique versus plated three-vertebra corpectomy for four-segment cervical myelopathy: analysis of 81 cases with a minimum 2-year follow-up. J Spinal Disord Tech. 2013.

47. Li Z, Huang J, Zhang Z, et al. A comparison of multilevel anterior cervical discectomy and corpectomy in patients with 4-level cervical spondylotic myelopathy: a minimum 2-year follow-up study. J Spinal Disord Tech. 2014.

48. Lau D, Chou D, Mummaneni PV. Two-level corpectomy versus three-level discectomy for cervical spondylotic myelopathy: a comparison of perioperative, radiographic, and clinical outcomes. J Neurosurg Spine. 2015;23:280-9.

49. Li F, Li Z, Huang X, et al. Comparison of two reconstructive techniques in the surgical management of four-level cervical spondylotic myelopathy. Biomed Res Int. 2015;2015:513906.

50. Liu J, Chen X, Liu Z, et al. Anterior cervical discectomy and fusion versus corpectomy and fusion in treating two-level adjacent cervical spondylotic myelopathy: a minimum 5-year follow-up study. Arch Orthop Trauma Surg. 2015;135:149-53.

51. Shamji MF, Massicotte EM, Traynelis VC, et al. Comparison of anterior surgical options for the treatment of multilevel cervical spondylotic myelopathy: a systematic review. Spine (Phila Pa 1976). 2013;38:S195-209.

52. Han YC, Liu ZQ, Wang SJ, et al. Is anterior cervical discectomy and fusion superior to corpectomy and fusion for treatment of multilevel cervical spondylotic myelopathy? A systemic review and meta-analysis. PLoS One. 2014;9:e87191.

53. Huang ZY, Wu AM, Li QL, et al. Comparison of two anterior fusion methods in two-level cervical spondylosis myelopathy: a meta-analysis. BMJ Open. 2014;4:e004581.

54. Wen ZQ, Du JY, Ling ZH, et al. Anterior cervical discectomy and fusion versus anterior cervical corpectomy and fusion in the treatment of multilevel cervical spondylotic myelopathy: systematic review and a meta-analysis. Ther Clin Risk Manag. 2015;11: 161-70.

55. Xiao SW, Jiang H, Yang LJ, et al. Anterior cervical discectomy versus corpectomy for multilevel cervical spondylotic myelopathy: a meta-analysis. Eur Spine J. 2015;24:31-9.

56. Hirabayashi K, Watanabe K, Wakano K, et al. Expansive opendoor laminoplasty for cervical spinal stenotic myelopathy. Spine (Phila Pa 1976). 1983;8:693-9.

57. Kurokawa T, Tsuyama N, Tanaka H, et al. Double-door laminoplasty. Bessatsu Seikeigeka. 1982;2:234-40.

58. Della Pepa GM, Roselli R, La Rocca G, et al. Laminoplasty is better of laminectomy in cervical stenotic myelopathy: myth or truth? Eur Rev Med Pharmacol Sci. 2014;18:50-4.

59. Yuan W, Zhu Y, Liu X, et al. Laminoplasty versus skip laminectomy for the treatment of multilevel cervical spondylotic myelopathy: a systematic review. Arch Orthop Trauma Surg. 2014;134:1-7.

60. Visocchi M, Della Pepa GM, Roselli R, et al. Laminoplasty and laminectomy in cervical stenotic myelopathy: allies not enemies. J Neurosurg Sci. 2014;58:101-5.

61. Bartels RH, Groenewoud H, Peul WC, et al. Lamifuse: results of a randomized controlled trial comparing laminectomy without and with fusion for cervical spondylotic myelopathy. J Neurosurg Sci. 2015.

62. Lao L, Zhong G, Li X, et al. Laminoplasty versus laminectomy for multi-level cervical spondylotic myelopathy: a systematic review of the literature. J Orthop Surg Res. 2013;8:45.
63. Bartels RH, van Tulder MW, Moojen WA, et al. Laminoplasty and laminectomy for cervical sponydylotic myelopathy: a systematic review. Eur Spine J. 2015;24 Suppl 2:160-7.

64. Miyamoto H, Maeno K, Uno K, et al. Outcomes of surgical intervention for cervical spondylotic myelopathy accompanying local kyphosis (comparison between laminoplasty alone and posterior reconstruction surgery using the screw-rod system). Eur Spine J. 2014;23:341-6.

65. Lin BJ, Lin MC, Lin C, et al. Image analysis of open-door laminoplasty for cervical spondylotic myelopathy: comparing the influence of cord morphology and spine alignment. Clin Neurol Neurosurg. 2015;137:72-8.

66. Maruo K, Moriyama T, Tachibana T, et al. The impact of dynamic factors on surgical outcomes after double-door laminoplasty for ossification of the posterior longitudinal ligament of the cervical spine. J Neurosurg Spine. 2014;21:938-43.

67. Yang L, Gu Y, Shi J, et al. Modified plate-only open-door laminoplasty versus laminectomy and fusion for the treatment of cervical stenotic myelopathy. Orthopedics. 2013;36:e79-87.

68. Lee CH, Jahng TA, Hyun SJ, et al. Expansive laminoplasty versus laminectomy alone versus laminectomy and fusion for cervical ossification of the posterior longitudinal ligament: is there a difference in the clinical outcome and sagittal alignment? J Spinal Disord Tech. 2014.

69. Yoon ST, Hashimoto RE, Raich A, et al. Outcomes after laminoplasty compared with laminectomy and fusion in patients with cervical myelopathy: a systematic review. Spine (Phila Pa 1976). 2013;38:S183-94.

70. Kiely PD, Quinn JC, Du JY, et al. Posterior surgical treatment of cervical spondylotic myelopathy: review article. HSS J. 2015;11: 36- 42.

71. Lee CH, Lee J, Kang JD, et al. Laminoplasty versus laminectomy and fusion for multilevel cervical myelopathy: a meta-analysis of clinical and radiological outcomes. J Neurosurg Spine. 2015;22: 589-95.

72.• Tetreault L, Ibrahim A, Cote P, et al. A systematic review of clinical and surgical predictors of complications following surgery for degenerative cervical myelopathy. J Neurosurg Spine. 2015:1-23. Systematic review investigating predictors of surgical complications for cervical myelopathy. They showed age and operative duration are key factors.

73. Starmer HM, Riley 3rd LH, Hillel AT, et al. Dysphagia, short-term outcomes, and cost of care after anterior cervical disc surgery. Dysphagia. 2014;29:68-77.

74. Fineberg SJ, Ahmadinia K, Oglesby M, et al. Hospital outcomes and complications of anterior and posterior cervical fusion with bone morphogenetic protein. Spine (Phila Pa 1976). 2013;38: 1304-9.

75. Singh K, Marquez-Lara A, Nandyala SV, et al. Incidence and risk factors for dysphagia after anterior cervical fusion. Spine (Phila Pa 1976). 2013;38:1820-5.

76. Jeyamohan SB, Kenning TJ, Petronis KA, et al. Effect of steroid use in anterior cervical discectomy and fusion: a randomized controlled trial. J Neurosurg Spine. 2015;23:137-43.

77. Yang H, Chen D, Wang X, et al. Zero-profile integrated plate and spacer device reduces rate of adjacent-level ossification development and dysphagia compared to ACDF with plating and cage system. Arch Orthop Trauma Surg. 2015;135:781-7.

78. Shriver MF, Lewis DJ, Kshettry VR, et al. Pseudoarthrosis rates in anterior cervical discectomy and fusion: a meta-analysis. Spine J. 2015;15:2016-27.

79. Shou F, Li Z, Wang H, et al. Prevalence of C5 nerve root palsy after cervical decompressive surgery: a meta-analysis. Eur Spine J. 2015;24:2724-34.

80. Odate S, Shikata J, Yamamura S, et al. Extremely wide and asymmetric anterior decompression causes postoperative C5 palsy: an 
analysis of 32 patients with postoperative C5 palsy after anterior cervical decompression and fusion. Spine (Phila Pa 1976). 2013;38:2184-9.

81. Wu FL, Sun Y, Pan SF, et al. Risk factors associated with upper extremity palsy after expansive open-door laminoplasty for cervical myelopathy. Spine J. 2014;14:909-15.

82. Lubelski D, Derakhshan A, Nowacki AS, et al. Predicting C5 palsy via the use of preoperative anatomic measurements. Spine J. 2014;14:1895-901.

83. Ohashi M, Yamazaki A, Watanabe K, et al. Two-year clinical and radiological outcomes of open-door cervical laminoplasty with prophylactic bilateral C4-C5 foraminotomy in a prospective study. Spine (Phila Pa 1976). 2014;39:721-7.

84. Riew KD, Raich AL, Dettori JR, et al. Neck pain following cervical laminoplasty: does preservation of the $\mathrm{C} 2$ muscle attachments and/or C7 matter? Evid Based Spine Care J. 2013;4:42-53.

85. Mori E, Ueta T, Maeda T, et al. Effect of preservation of the C-6 spinous process and its paraspinal muscular attachment on the prevention of postoperative axial neck pain in C3-6 laminoplasty. J Neurosurg Spine. 2015;22:221-9.

86. Harman F, Kaptanoglu E, Hasturk AE. Esophageal perforation after anterior cervical surgery: a review of the literature for over half a century with a demonstrative case and a proposed novel algorithm. Eur Spine J. 2016.

87. Lunardini DJ, Eskander MS, Even JL, et al. Vertebral artery injuries in cervical spine surgery. Spine J. 2014;14:1520-5.

88. Tan TP, Govindarajulu AP, Massicotte EM, et al. Vocal cord palsy after anterior cervical spine surgery: a qualitative systematic review. Spine J. 2014;14:1332-42.

89. Grossman RG, Fehlings MG, Frankowski RF, et al. A prospective, multicenter, phase I matched-comparison group trial of safety, pharmacokinetics, and preliminary efficacy of riluzole in patients with traumatic spinal cord injury. J Neurotrauma. 2014;31:23955 .

90. Moon ES, Karadimas SK, Yu WR, et al. Riluzole attenuates neuropathic pain and enhances functional recovery in a rodent model of cervical spondylotic myelopathy. Neurobiol Dis. 2014;62:394 406.

91. Karadimas SK, Laliberte AM, Tetreault L. Riluzole blocks perioperative ischemia-reperfusion injury and enhances postdecompression outcomes in cervical spondylotic myelopathy. Sci Transl Med. 2015;7:316ra194.

92. Fehlings MG, Wilson JR, Karadimas SK, et al. Clinical evaluation of a neuroprotective drug in patients with cervical spondylotic myelopathy undergoing surgical treatment: design and rationale for the CSM-Protect trial. Spine (Phila Pa 1976). 2013;38:S6875. Describes the ongoing project investigating the effectiveness of neuroprotective agent as a new modality of treatment augmentation.

93. Pumberger M, Froemel D, Aichmair A, et al. Clinical predictors of surgical outcome in cervical spondylotic myelopathy: an analysis of 248 patients. Bone Joint J. 2013;95-B:966-71.

94.• Tetreault LA, Kopjar B, Vaccaro A, et al. A clinical prediction model to determine outcomes in patients with cervical spondylotic myelopathy undergoing surgical treatment: data from the prospective, multi-center AOSpine North America study. J Bone Joint Surg Am. 2013;95:1659-66. Prediction model developed from multicenter prospective data. They identified a list of seven predictors of surgical outcome for cervical myelopathy.

95. Yoon ST, Raich A, Hashimoto RE, et al. Predictive factors affecting outcome after cervical laminoplasty. Spine (Phila Pa 1976). 2013;38:S232-52.

96. Techy F, Benzel EC. Predictors of outcome in patients with cervical spondylotic myelopathy undergoing surgical treatment: the evidence and the international common practice. World Neurosurg. 2014;81:503-7.
97. Tetreault LA, Nouri A, Singh A, et al. Predictors of outcome in patients with cervical spondylotic myelopathy undergoing surgical treatment: a survey of members from AOSpine International. World Neurosurg. 2014;81:623-33.

98. Tetreault LA, Cote P, Kopjar B, et al. A clinical prediction model to assess surgical outcome in patients with cervical spondylotic myelopathy: internal and external validations using the prospective multicenter AOSpine North American and international datasets of 743 patients. Spine J. 2015;15:388-97.

99. Tetreault LA, Karpova A, Fehlings MG. Predictors of outcome in patients with degenerative cervical spondylotic myelopathy undergoing surgical treatment: results of a systematic review. Eur Spine J. 2015;24 Suppl 2:236-51.

100. Kang J, Shi C, Gu Y, et al. Factors that may affect outcome in cervical artificial disc replacement: a systematic review. Eur Spine J. 2015;24:2023-32.

101. Karpova A, Arun R, Davis AM, et al. Predictors of surgical outcome in cervical spondylotic myelopathy. Spine (Phila Pa 1976). 2013;38:392-400.

102. Tetreault L, Nouri A, Singh A, et al. An assessment of the key predictors of perioperative complications in patients with cervical spondylotic myelopathy undergoing surgical treatment: results from a survey of 916 AOSpine International Members. World Neurosurg. 2015;83:679-90.

103. Chen Y, Yang L, Liu Y, et al. Surgical results and prognostic factors of anterior cervical corpectomy and fusion for ossification of the posterior longitudinal ligament. PLoS One. 2014;9: e102008.

104. Gu Y, Shi J, Cao P, et al. Clinical and imaging predictors of surgical outcome in multilevel cervical ossification of posterior longitudinal ligament: an analysis of 184 patients. PLoS One. 2015;10:e136042.

105. Xing D, Wang J, Ma JX, et al. Qualitative evidence from a systematic review of prognostic predictors for surgical outcomes following cervical ossification of the posterior longitudinal ligament. J Clin Neurosci. 2013;20:625-33.

106. Shamji MF, Ames CP, Smith JS, et al. Myelopathy and spinal deformity: relevance of spinal alignment in planning surgical intervention for degenerative cervical myelopathy. Spine (Phila Pa 1976). 2013;38:S147-8.

107. Scheer JK, Tang JA, Smith JS, et al. Cervical spine alignment, sagittal deformity, and clinical implications: a review. J Neurosurg Spine. 2013;19:141-59.

108. Smith JS, Lafage V, Ryan DJ, et al. Association of myelopathy scores with cervical sagittal balance and normalized spinal cord volume: analysis of 56 preoperative cases from the AOSpine North America Myelopathy study. Spine (Phila Pa 1976). 2013;38:S161-70.

109. Mohanty C, Massicotte EM, Fehlings MG, et al. Association of preoperative cervical spine alignment with spinal cord magnetic resonance imaging hyperintensity and myelopathy severity: analysis of a series of 124 cases. Spine (Phila Pa 1976). 2015;40:11-6.

110. Tang JA, Scheer JK, Smith JS, et al. The impact of standing regional cervical sagittal alignment on outcomes in posterior cervical fusion surgery. Neurosurgery. 2012;71:662-9. discussion 9.

111. Taniyama T, Hirai T, Yoshii T, et al. Modified K-line in magnetic resonance imaging predicts clinical outcome in patients with nonlordotic alignment after laminoplasty for cervical spondylotic myelopathy. Spine (Phila Pa 1976). 2014;39:E1261-8.

112. Shamji MF, Mohanty C, Massicotte EM, et al. The association of cervical spine alignment with neurological recovery in a prospective cohort of surgical myelopathy patients: analysis of a series of 124 cases. World Neurosurg. 2015. Prospective study that showed cervical sagittal alignment has an impact on postoperative neurological recovery. 